\title{
Transketolase Abnormality in Cultured Fibroblasts from Familial Chronic Alcoholic Men and Their Male Offspring
}

\author{
Anil B. Mukherjee, Soraya Svoronos, Amir Ghazanfari, Peter R. Martin,“ Alice Fisher, Bryan Roecklein, David Rodbard, \\ Richard Staton," David Behar, Carol J. Berg, and Ramanathapuram Manjunath \\ Section on Developmental Genetics, Human Genetics Branch, National Institute of Child Health and Human Development, \\ National Institutes of Health, *Laboratory of Clinical Studies, National Institute on Alcohol Abuse and Alcoholism, \\ ${ }^{\ddagger}$ Laboratory of Theoretical and Physical Biology, National Institute of Child Health and Human Development, \\ and ${ }^{\S}$ National Institute of Mental Health, Bethesda, Maryland 20892
}

\begin{abstract}
We have investigated a thiamine-dependent enzyme, transketolase, in cultured fibroblasts from 41 human subjects, including patients with alcoholism-associated Wernicke-Korsakoff syndrome $(n=3)$, familial chronic alcoholic males $(n=7)$, their sons $(n=7)$, nonalcoholic men $(n=7)$, their male offspring ( $n$ $=7$ ), and three generations of an Amish family $(n=10)$ without any history of alcoholism. This study was undertaken to delineate whether transketolase abnormality (i.e., high Michaelis Menton constant $\left(K_{m}\right)$ for thiamine pyrophosphate), previously reported in patients with Wernicke-Korsakoff syndrome is prevalent among familial chronic alcoholic men and their sons without prior history of alcohol abuse but who are at high risk for alcoholism. Our data suggest that an inborn error (i.e., high $K_{\mathrm{m}}$ of transketolase for thiamine pyrophosphate) predisposing to thiamine deficiency diseases similar to those reported in Wernicke-Korsakoff syndrome may occur in the general population. However, for some as yet unexplained reason(s) this variant seems to occur more frequently among familial chronic alcoholic men and their male offspring without any history of alcoholism. The inheritance pattern of this enzyme variant as revealed from an Amish pedigree study may be autosomal recessive as previously suggested.
\end{abstract}

\section{Introduction}

Chronic alcoholism and its complications contribute significantly to medical and public health programs throughout the world. The development of this disease, like that of most diseases, has been suggested to be a complex interaction between socio-environmental situation, the individual at risk, and availability of alcohol (1). There is substantial evidence to suggest that availability of alcohol is not enough to develop either chronic alcoholism or all of its complications, and predisposing genetic factors may be involved (2-4).

It is well known that one of the complications of chronic alcoholism, thiamine (vitamin $B_{1}$ ) deficiency, leads to WernickeKorsakoff syndrome (5). It has been reported by Blass and Gibson (6) that a thiamine-requiring enzyme, transketolase (E.C. 2.2.1.1) from skin fibroblasts of patients with alcoholism-related Wernicke-Korsakoff syndrome bound its co-factor, thiamine pyro-

Address reprint requests to Dr. Anil B. Mukherjee, Section on Developmental Genetics, Human Genetics Branch, Building 10, Room 8C429, National Institutes of Health, Bethesda, MD 20892.

Received for publication 18 August 1986.

The Journal of Clinical Investigation, Inc.

Volume 79, April 1987, 1039-1043 phosphate (TPP) ${ }^{1}$ less avidly (i.e., high Michaelis-Menten constant $\left[K_{\mathrm{m}}\right]$ for TPP) than the enzyme from control fibroblasts. It was also suggested that the observed abnormality in transketolase in this syndrome is genetic rather than the result of the condition (6). These suggestions were made on the basis of $(a)$ persistence of this enzyme abnormality (i.e., high $K_{\mathrm{m}}$ for TPP) in tissue-cultured cells through serial passages, and $(b)$ the presence of this abnormality even when the cells were cultured in medium containing excess thiamine and no ethanol.

The majority of patients with Wernicke-Korsakoff syndrome have a history of chronic alcohol abuse. Also there is compelling evidence to suggest that the risk of chronic alcoholism is significantly higher in male children with an alcoholic biologic parent (3-6). The sons of alcoholics have $\sim 25 \%$ (5\% expected) and daughters $\sim 5 \%$ ( $1 \%$ expected) risk of developing alcoholism (4).

In the present investigation we attempted to delineate whether or not transketolase abnormality, previously reported in Wernicke-Korsakoff syndrome, is prevalent in familial chronic alcoholic males and whether or not such abnormality, if present, is detectable in their sons without any history of alcohol abuse. We also studied three generations of a nonalcoholic Amish family to delineate whether or not abnormal transketolase occurred in the absence of alcoholism and the possible mode of inheritance of the enzyme variant. In addition to confirming the original observations of Blass and Gibson (7) in three of our own Korsakoff patients, we now report the existence of a similar transketolase abnormality in familial chronic alcoholic males and their sons who did not have any history of alcohol abuse.

Additionally, the results of the Amish family pedigree study suggest that $(a)$ transketolase abnormality may also occur in the nonalcoholic population, and $(b)$ it is present in both the male and female sibs as may be expected in an autosomal recessive type of inheritance as previously suggested.

\section{Methods}

The criteria for patient selection and their detailed descriptions have been published elsewhere (8). Briefly, parents with children between 8 and $15 \mathrm{yr}$ of age who were interested in participating in the study were recruited from the area alcohol treatment facilities. A total of 12 parents (father in 8 cases, mothers in 2 cases, and both in 1) who met Feighner criteria (9) for primary "definite" alcoholism were included. The criterion of familial alcoholism was met when there was a history of the disease for at least two generations. Age-matched controls from a similar socio-

1. Abbreviations used in this paper: ANOVA, analysis of variance; GSH, glutathione; HMP, hexose monophosphate; TPP, thiamine pyrophosphate. 
economic environmental background to those of the alcoholic parents were recruited from the community.

All children had at least one alcoholic drink in their lives and none had sipped on more than five occasions. These children were free from any ongoing medical or psychiatric problems. The mean age of control children was $11.75 \pm 2.16$ (SD) yr, whereas that of alcoholics' children was $12.25 \pm 2.3 \mathrm{yr}$. The weights of control and alcoholics' children were $42.2 \pm 13.3 \mathrm{~kg}$ and $49.2 \pm 18.1 \mathrm{~kg}$, respectively. The IQ of the control children was $118 \pm 9$, whereas that of alcoholics' children was $123 \pm 14$. The socio-economic class as determined by using criteria of Hollingshead and Redlick (10) was almost identical for the two groups.

The control children had negative family histories for psychiatric disorders, alcoholism, or sociopathy as far back as could be reasonably ascertained. One child in the control group carried a diagnosis of attention deficit disorder with hyperactivity.

Korsakoff patients. Three white males (ages 59, 60, 63), long-term patients at the United States Soldiers' and Airmen's Home, Washington, DC with past histories of heavy chronic alcohol consumption, had a clinically stable amnestic disorder for at least $6 \mathrm{mo}$. According to the referring physician, none of these patients had consumed alcohol within the past $6 \mathrm{mo}$, and all had adequate nutrition before admission at the National Institutes of Health Clinical Center. Patients were hospitalized at the National Institutes of Health for 2-4 mo before skin biopsy. All patients fulfilled clinical criteria for Korsakoff psychosis (11) and also had characteristic abnormalities on research tests of learning and memory (12). None of these patients had any significant cardiovascular, renal, endocrine, or hepatic disease and they were not on any medications at the time the skin biopsies were obtained.

Skin biopsy and cell culture. Informed consent was obtained from each subject before skin biopsy.

Under 2\% lidocaine anesthesia a 3-mm skin biopsy was obtained from the upper arm. Primary cultures were established in RPMI-1640 medium (HEM Research, Rockville, MD) supplemented with $10 \%$ heatinactivated fetal calf serum (Gibco Laboratories, Grand Island, NY) and $10 \mathrm{mM}$ glutamine but no antibiotics were used. When confluent, these cells were trypsinized and propagated first into $75-\mathrm{cm}^{2}$ and then $175-$ $\mathrm{cm}^{2}$ plastic tissue culture flasks (Corning Science Products, Corning, NY). Although attempts were made to establish fibroblast cultures from all patients, successful cultures were obtained from skin biopsies of seven alcoholic fathers and their sons and eight nonalcoholic fathers and seven of their male offspring. Fibroblast cultures were successful in all three Wernicke-Korsakoff patients. The cells were matched for passage numbers as much as practicable. The growth medium contained enough thiamine $(0.95 \mu \mathrm{g} / \mathrm{ml})$ that after $3 \mathrm{~d}$ of growth it was not totally depleted of thiamine $(0.20 \mu \mathrm{g} / \mathrm{ml})$. Thus, no additional thiamine supplementation was required for this medium. No alcohol was added to the cultures. The cells were used for biochemical studies when they were between the fourth and eighth passages in culture. The passage number had no effect on the activity of transketolase or its $K_{\mathrm{m}}$ for TPP for a particular cell line. The clinical diagnosis of all patients contributing skin biopsies was unknown to laboratory personnel who performed tissue culture and/or enzyme assays.

Because in the present investigation only father/son groups were included in our protocol, we decided to study a nonalcoholic family pedigree to delineate the incidence and the pattern of inheritance of this enzyme abnormality in such a population. Fibroblast cultures from 10 individuals representing three generations of an Amish family (Family 884) were obtained from the Human Genetics Cell Repository, Institute for Medical Research, Camden, NJ. This family had a history of affective disorders but no alcoholism (Dr. J. A. Egeland, personal communication). As shown in Fig. 4 only the shaded portion of the pedigree has been studied.

Experimental procedure. The procedures for transketolase assay and $K_{\mathrm{m}}$ determination used in this study were the same as previously described (7) with minor modifications. Briefly, confluent fibroblast cultures from four $175-\mathrm{cm}^{2}$ flasks were harvested with trypsin $(0.025 \% \mathrm{wt} / \mathrm{vol})$ centrifuged at $600 \mathrm{~g}$ for $10 \mathrm{~min}$ and washed twice with phosphate buffered saline (HEM Research) at $\mathrm{pH} 7.4$ at room temperature.

The washed cell pellet was sonicated in $4.1 \mathrm{ml}$ of $40 \mathrm{mM}$ potassium phosphate, $\mathrm{pH} 7.0$, and the final volume was adjusted to $4.5 \mathrm{ml}$ with glycerol. An aliquot of $0.5 \mathrm{ml}$ was removed and used for assaying total transketolase activity. The remainder of the homogenate, $4 \mathrm{ml}$, was kept on ice, and $3.3 \mathrm{ml}$ of saturated ammonium sulfate was added and the $\mathrm{pH}$ readjusted to 3.5 with $0.5 \mathrm{mM}$ sulfuric acid. The sample was centrifuged at $40,000 \mathrm{~g}$ for $40 \mathrm{~min}$ and the pellet was resuspended in $1 \mathrm{ml}$

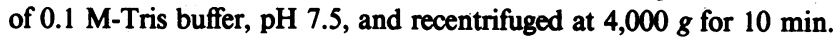
The supernatant was used to determine $K_{\mathrm{m}}$ for TPP.

The final reaction mixture contained $100 \mathrm{mM}$ Tris, pH 7.5, $10 \mathrm{mM}$ ribose-5-phosphate, $2 \mathrm{mM}$ xylulose-5-phosphate, $1.2 \mathrm{mM}$ magnesium chloride, $0.1 \mathrm{mM} \mathrm{NADH}, 1 \mathrm{U}$ of triose phosphate isomerase (E.C. 5.4.1.1; Sigma Chemical Co., St. Louis, MO), glycerol phosphate dehydrogenase (E.C. 1.1.1.8; Sigma Chemical Co.), and varying concentrations of TPP in a total volume of $0.5 \mathrm{ml}$. All assays were done at room temperature $\left(23^{\circ} \mathrm{C}\right.$ ). A spectrophotometer (model 35; Beckman Instruments, Inc., Fullerton, CA) was used to measure the activity of transketolase. Total protein was then determined by the method of Lowry et al. (13). The apparent $K_{\mathrm{m}}$ was determined by constructing the Lineweaver-Burk plot from a weighted linear regression of all the data points (correlation coefficient, > 0.95).

Statistical analysis of data. Data were first analysed by an analysis of variance (ANOVA) $(2 \times 3$ factorial design) and Duncan's multiple range test. In view of apparent non-Gaussian distribution despite use of several transforms, nonparametric methods were also applied (ANOVA based on ranks, Wilcoxon rank sum test, median two-sample test). Bartlett's test was used to evaluate homogeneity of variance, and pooled variance estimates were used to improve reliability (i.e., increasing the number of degrees of freedom). Additionally, all data were tested by paired or unpaired two-tailed $t$ tests, as appropriate. Analyses were done with SAS and the BRIGHT STAT PACK (14).

\section{Results}

The amount of fibroblast protein used in our assay was $180 \mu \mathrm{g}$. Enzyme activity was proportional to incubation time up to 10 min. The dependence of both crude and acid ammonium sulfate-extracted enzyme activity on added cofactors is shown in Table I. Removal of endogenous thiamine pyrophosphate in the acid ammonium sulfate extract resulted in no detectable activity of transketolase. This suggests a total dependence of this enzyme on added TPP and the efficiency with which the acid ammonium sulfate removes the cofactor from the holoenzyme. The enzyme activity was not totally dependent on exogenous ribose-5-phos-

Table I. Cofactor Requirements for Transketolase Activity

\begin{tabular}{lll}
\hline Reactants & Crude extract & $\begin{array}{l}\text { Ammonium sulfate } \\
\text { extract }\end{array}$ \\
\hline & $\%$ control & $\%$ control \\
$\begin{array}{l}\text { Complete reaction mixture } \\
\text { (control) }\end{array}$ & 100 & 100 \\
$\begin{array}{l}\text { Minus TPP } \\
\text { Minus ribose-5-phosphate }\end{array}$ & $98-100$ & ND \\
$\begin{array}{l}\text { Minus xylulose-5-phosphate } \\
\text { Minus ribose-5-phosphate and } \\
\text { xylulose-5-phosphate }\end{array}$ & $5-10$ & $0-8$ \\
$\begin{array}{l}\text { Minus NADH } \\
\text { Minus triose phosphate } \\
\text { isomerase and glycerol } \\
\text { phosphate dehydrogenase }\end{array}$ & ND & $3-4$ \\
Minus $\mathrm{MgCl}_{2}$ & ND & ND \\
& ND & \\
\hline
\end{tabular}

ND, activity not detectable. 

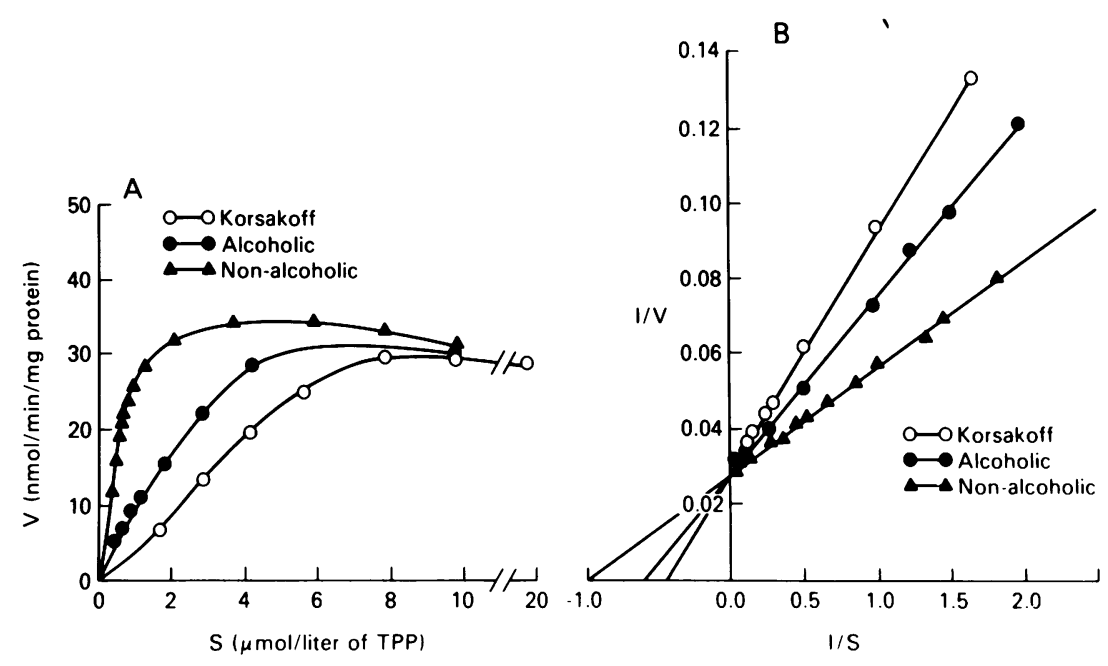

Figure 1. Determination of apparent $K_{\mathrm{m}}$ of transketolase for TPP. $K_{\mathrm{m}}$ was determined by constructing a double reciprocal or Lineweaver-Burk plot $(B)$. This plot was obtained by regression analysis of all the data points (correlation coefficient, $>0.95$ ). Note the $K_{\mathrm{m}}$ differences between a representative nonalcoholic father (triangles), familial chronic alcoholic man (solid circles), and a patient with Wernicke-Korsakoff syndrome (open circles). phate or xylulose-5-phosphate. However, when both of these pentoses were omitted simultaneously from the reaction mixture there was no detectable enzyme activity. Similarly, omission of $\mathrm{NADH}$, triose phosphate isomerase, or glycerol phosphate dehydrogenase resulted in no detectable activity.

The apparent $K_{\mathrm{m}}$ for binding TPP for transketolase was strikingly different among the three groups of subjects investigated (Fig. 1). The difference between the apparent $K_{\mathrm{m}}$ of this enzyme for TPP was highly significant $(P=0.0001)$ between the Korsakoff, alcoholic, and control groups using the parametric ANOVA and the ANOVA based on ranks. As shown in Fig. 2 $A$, the $K_{\mathrm{m}}$ values for children of alcoholics (mean $K_{\mathrm{m}}, 1.80 \mu \mathrm{mol} /$ liter) were significantly higher than those of the control children (mean $K_{\mathrm{m}}, 0.96 \mu \mathrm{mol} /$ liter; $P<0.01$ ). Duncan's test confirmed that all three groups, i.e., nonalcoholic father/son, alcoholic father/son, and the Korsakoff patients were statistically different $(P<0.01)$ in terms of their apparent $K_{\mathrm{m}}$ for TPP for transketolase. Mean $K_{\mathrm{m}}$ for the nonalcoholic fathers was $0.97 \mu \mathrm{mol} /$ liter, not significantly different from their sons $(P>0.05)$. However, in one nonalcoholic father and his son we observed a $K_{\mathrm{m}}$ abnormality similar to alcoholic father/son groups (Fig. $2 \mathrm{~B}$ ). Mean $K_{\mathrm{m}}$ value for the enzyme of alcoholic fathers was $2.0 \mu \mathrm{mol} /$ liter, not significantly different from the mean $K_{\mathrm{m}}$ of the enzyme of their sons $(P>0.05)$, except in one instance where an alcoholic father with a high $K_{\mathrm{m}}$ had a son with a low $K_{\mathrm{m}}$ enzyme (Fig. 2 $B$ ). These results were confirmed by nonparametric two-sample Wilcoxon rank sum test and the median two-sample test. No correlation was found between either the activity or the $K_{\mathrm{m}}$ of this enzyme for TPP and age of the subjects studied (Fig. 3, $A$ and $B$ ).

The family pedigree study revealed that the abnormal transketolase $K_{\mathrm{m}}$ for TPP was present in both the male and female members of the family (Fig. 4).

\section{Discussion}

Our data demonstrate that, compared to nonalcoholic controls, transketolase abnormality (i.e., high $K_{\mathrm{m}}$ for TPP) may occur more frequently among familial chronic alcoholic males and their male offspring who had no prior history of ethanol abuse. Thus, our data, in addition to confirming the results of Blass and Gibson (7), suggest that this enzyme abnormality may not be the result of chronic alcohol abuse. Additionally, persistence of this abnormality in serial passages of tissue-cultured cells may suggest a genetic abnormality. The results of the family pedigree study may support such an argument. Transketolase is a key enzyme in the hexose monophosphate (HMP) shunt pathway of glucose metabolism (15), and TPP is an essential cofactor for functioning of this enzyme (16). It is believed that one of the major functions of the HMP shunt is to generate ribose-5-phosphate and reduced NADPH (17). The ribose-5-phosphate is vital for nucleic acid synthesis and the NADPH plays an indispensible role in maintaining cerebral glutathione in the reduced state $(15$, 18). Because one of the suggested properties of reduced glutathione (GSH) is to maintain metabolically important thiol compounds in the reduced form to assure their function as coenzymes
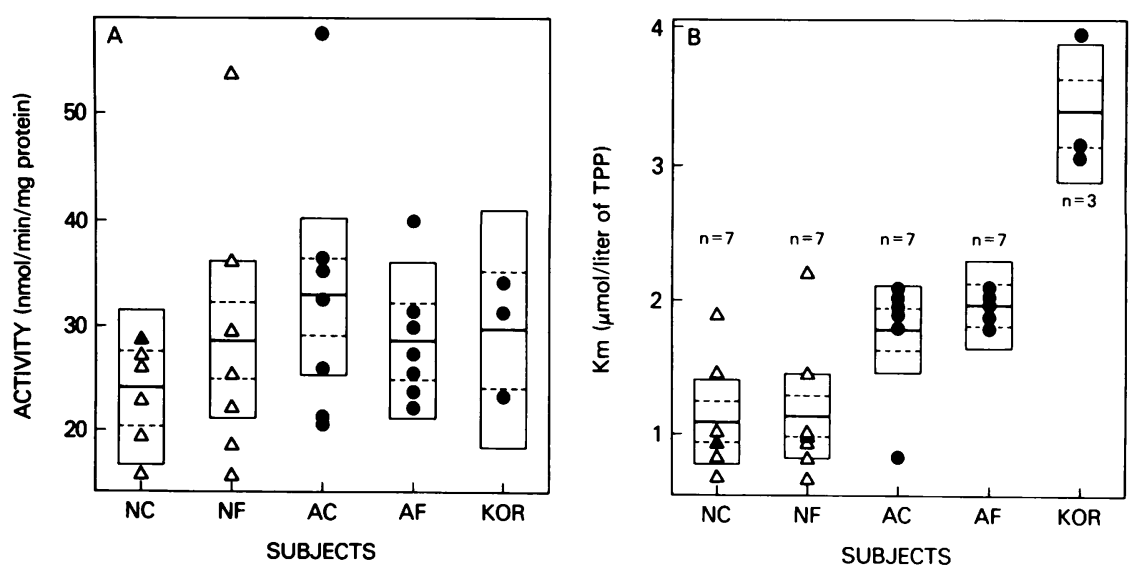

Figure 2. Comparison of apparent $K_{\mathrm{m}}$ of transketolase for TPP $(A)$ and transketolase activity $(B)$ in all groups. NC, sons of nonalcoholic fathers; NF, nonalcoholic fathers; $A C$, sons of alcoholic fathers; AF, alcoholic fathers; KOR, Korsakoff patients. The center horizontal bar represents the mean, the outer bars denote the $95 \%$ pooled confidence limits, and the dashed lines represent the mean \pm 1 SEM. 

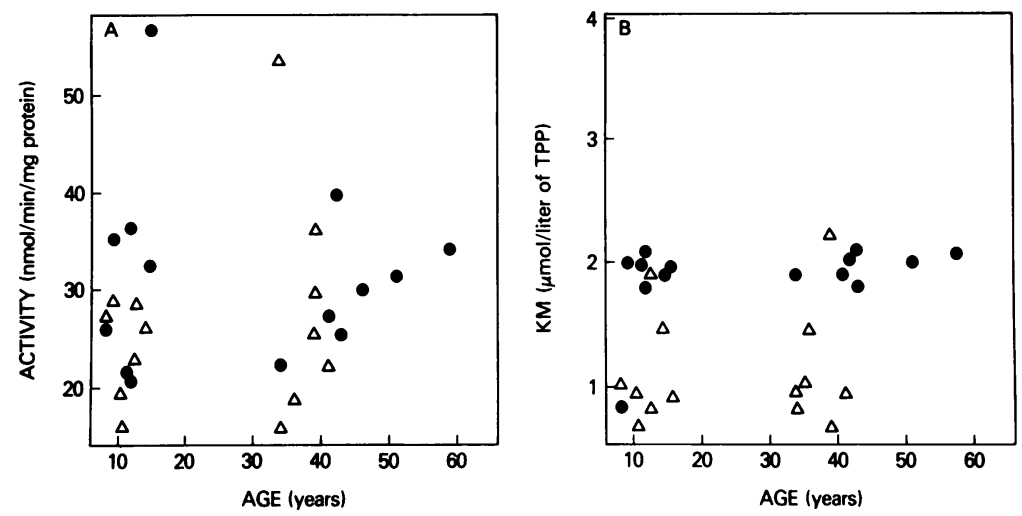

Figure 3. Effect of age on activity $(A)$ and $K_{\mathrm{m}}(B)$ of transketolase. (Circles), alcoholic fathers and sons; (triangles), nonalcoholic fathers and sons.

and enzymes (18), a reduction in the synthesis of NADPH would result in decreased GSH and thus seriously impair the function of several cerebral metabolic pathways. The earliest well documented change in thiamine deficiency is a decrease in transketolase activity $(19,20)$ and a fall in erythrocyte and myocardial GSH (21). This may suggest that individuals with a high $K_{\mathrm{m}}$ enzyme are more susceptible to developing functional thiamine deficiency than are those individuals with a low $K_{\mathrm{m}}$ enzyme. This is because a high $K_{\mathrm{m}}$ enzyme requires higher concentration of TPP to generate the same activity that a low $K_{\mathrm{m}}$ enzyme would produce at a much lower concentration. In light of this explanation our data could be interpreted to mean that the chronic alcoholic men and their sons frequently with a higher transketolase $K_{\mathrm{m}}$ for TPP would develop symptoms of thiamine deficiency much earlier than those with a low $K_{\mathrm{m}}$ enzyme in a scenario of alcohol abuse.

The $K_{\mathrm{m}}$ abnormality found in one nonalcoholic father and his son and the results of the Amish family pedigree study suggest that this enzyme phenotype is not an indicator of alcoholism but more likely a marker for predisposition to develop thiamine deficiency disease should these individuals abuse ethanol. Although in the present investigation the intermediate $K_{\mathrm{m}}$ values were observed most frequently among alcoholic fathers and their sons and the low $K_{\mathrm{m}}$ values were characteristic of nonalcoholic father/son groups, the family pedigree study (Fig. 4) revealed that this abnormality may also occur in nonalcoholic families. Because the observed enzyme abnormality (high $K_{\mathrm{m}}$ phenotype) occurred both in male and female members of this pedigree and since two of the four Wernicke-Kossakoff patients studied by Blass and Gibson (7) were females, this may presumably be an autosomal recessive disorder as already suggested by McKusick (22). Although it is not clear why there is a clustering of high
$K_{\mathrm{m}}$ phenotype among alcoholic fathers and their sons, the present investigation underscores the need for large-family pedigree studies. In the present investigation, quantitatively small variations in apparent $K_{\mathrm{m}}$ were observed between three groups studied. This may, nonetheless, indicate larger and functionally significant differences in other kinetic measures, such as the association constant for TPP.

The present investigation has several limitations that must be acknowledged: $(a)$ the sample size is somewhat small, $(b)$ complete $K_{\mathrm{m}}$ data on alcoholic families are lacking although the nonalcoholic family pedigree study reveals an autosomal recessive type of inheritance, and $(c)$ it is not clear whether the $K_{\mathrm{m}}$ of the fibroblast enzyme reflects the $K_{\mathrm{m}}$ of the enzyme in the neuronal tissues where the effects of thiamine deficiency are most pronounced. However, it may be mentioned that recently several similarities have been described between fibroblasts and neuronal tissues (23). One other limitation with this type of study is distinguishing between genetic variation and abnormality when dealing with genetically determined changes that lead to disease processes only in certain environmental contexts. Our data clearly indicate that there is variation in the apparent $K_{\mathrm{m}}$ for TPP in human transketolase, and the Amish family study suggests that this variation may be inherited in an autosomal recessive pattern. The data also indicate an association of the highest $K_{\mathrm{m}}$ values (i.e., poorest binding of TPP) with Wernicke-Korsakoff syndrome. The unresolved question is whether or not the $K_{\mathrm{m}}$ values that cluster around 2, in both the alcoholics and their offspring and some of the Amish kindreds, should be called " $a b$ normal" or "variant."

The transketolase $K_{\mathrm{m}}$ values from normal control fibroblasts as well as fibroblasts of Wernicke-Korsakoff syndrome are much lower in the present investigation than those reported by Blass

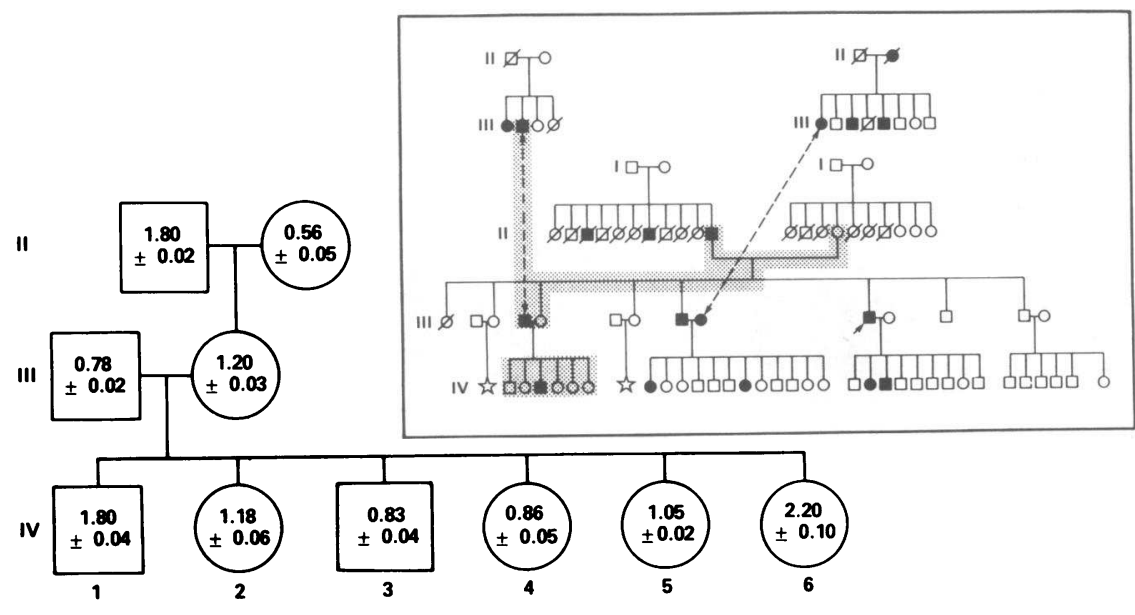

Figure 4. Pattern of inheritance of $K_{\mathrm{m}}$ for TPP for transketolase in three generations of a family. The shaded portion of the pedigree has been studied. Note that the abnormal $K_{\mathrm{m}}$ occurs in both male and female members of this pedigree. 
and Gibson (7). The reason for this discrepancy, although not fully clear, may be due to $(a)$ the presence of impurities in reactants, especially ribose-5-phosphate and xylulose-5-phosphate in the former study, and/or $(b)$ the shorter preincubation time with coupling enzymes, $\mathrm{MgCl}_{2}$, and the other components of the reaction minus TPP in the present investigation. However, in our hands, the shorter preincubation did not seem to influence the assay adversely. Nonetheless, our results clearly indicate a difference in kinetics between the Wernicke-Korsakoff enzyme and that from normal controls as previously reported by Blass and Gibson (7). Furthermore, the $K_{\mathrm{m}}$ values in our study have a very small standard deviation suggesting less variability and therefore more reliable measurement.

The existence of a relationship between inborn predispositions and environmental factors has been well recognized in many diseases (24). However, a direct cause-and-effect relationship between these interactions has been delineated in only a few. Clinical and epidemiologic observations have suggested the existence of genetic predispositions to specific complications of alcoholism (25). The present investigation, in addition to lending support to the above view, raises several important questions. (a) Do familial chronic alcoholics represent a genetic group more susceptible to developing thiamine deficiency disease such as Wernicke-Korsakoff syndrome? $(b)$ Is this abnormality specifically related to central nervous system complications of thiamine deficiency or are similar abnormalities also present in patients who are afflicted with nutritional neuropathy? (c) Because Wernicke-Korsakoff syndrome can be present in the absence of chronic alcoholism does transketolase abnormality occur in these patients as well? The last question is partially answered because we recently found that a diabetic who developed Wernicke's encephalopathy also has an abnormal transketolase $K_{m}$ similar to Wernicke-Korsakoff patients (26).

The present biochemical observations on the occurrence of transketolase abnormality predominantly in familial chronic alcoholic males and their sons are striking in that these children had no prior history of alcohol abuse. Although the results of our investigation do not allow inference that transketolase abnormality predisposes these children to develop alcoholism in the future, they do underscore the necessity of longitudinal studies to prove or disprove such a relationship.

\section{Acknowledgments}

We thank Drs. J. Barranger, J. Rapoport, E. Gershon, M. Zasloff, J. Sidbury, J. Schulman and M. M. Cohen for critical review of this manuscript. We also thank Dr. Egeland for confirming that no member of the Amish pedigree was an alcoholic. We thank Ms. Colleen Genovese and Ms. Ruth Mastromarino for excellent secretarial assistance.

This work was supported in part by a grant from the Laboratory of Clinical Studies, Division of Intramural Research, National Institute of Alcohol Abuse and Alcoholism.

\section{References}

1. Mendelson, J. H., and N. K. Mello. 1979. Biologic concommitants of alcoholism. N. Engl. J. Med. 301:912-921.

2. Omenn, G. S., and A. G. Motulsky. 1972. A biochemical and genetic approach to alcoholism. Ann. N. Y. Acad. Sci. 197:16-23.
3. Shuckit, M. A., D. A. Goodwin, and G. Winokur. 1972. A study of alcoholism in half siblings. Am. J. Psychiatry. 128:1132-1136.

4. Goodwin, D. W. 1979. Genetic determinants of alcoholism. In The Diagnosis and Treatment of Alcoholism. J. H. Mendelson and N. K. Mellow, editors. McGraw-Hill Book Co., New York. 59-82.

5. Victor, M., and R. D. Adams. 1961. On the etiology of the alcoholic neurologic diseases with special reference to the role of nutrition. Am. J. Clin. Nutr. 9:379-397.

6. Cadoret, R. J., and A. Gath. 1978. Inheritance of alcoholism in adoptees. Br. J. Psychiatry. 132:252-258.

7. Blass, J. P., and G. E. Gibson. 1977. Abnormality of a thiaminerequiring enzyme in patients with Wernicke-Korsakoff syndrome. $N$. Engl. J. Med. 297:1367-1370.

8. Behar, D., C. J. Berg, J. L. Rapoport, W. Nelson, M. Linnoila, M. Cohen, C. Bozevich, and T. Marshall. 1983. Behavioral and physiological effects of ethanol in high-risk and control children: a pilot study. Alcohol. Clin. Exp. Res. 7:404-410.

9. Feighner, J. P., E. Robins, S. B. Guze, R. A. Woodruff, Jr., G. Winokur, and R. Munoz. 1972. Diagnostic criteria for use in psychiatric research. Arch. Gen. Psychiatry. 26:57-63.

10. Hollingshead, A. B., and F. C. Redlich. 1958. Social Class and Mental Illness. John Wiley \& Sons, New York.

11. Victor, M., R. D. Adams, and G. H. Collins. 1971. The WernickeKorsakoff Syndrome. Davis, Philadelphia.

12. Weingartner, H., J. Grafman, W. Boutelle, W. Kaye, and P. R. Martin. 1983. Forms of memory failure. Science (Wash. DC). 221:380382.

13. Lowry, O. H., N. J. Rosebrough, A. L. Farr, and R. J. Randall. 1951. Protein measurement with the folin phenol reagent. J. Biol. Chem. 193:265-275.

14. Rodbard, D., B. R. Cole, and P. J. Munson. 1983. Development of a friendly, self-teaching, interactive statistical package for analysis of clinical research data: The BRIGHT STAT PACK. Seventh Annual Symposium on Computer Application and Medical Care. R. E. Dayhoff, editor. IEEE Computer Society Press, Silver Spring, MD. 701-704.

15. Mcllwain, H. 1966. Biochemistry and the Central Nervous System. Little, Brown and Co., Boston. Third ed. 167-176.

16. Horecker, B. L., and P. Z. Smyrniotis. 1953. The coenzyme function of thiamine pyrophosphate in penose phosphate metabolism. $J$. Am. Chem. Soc. 75:1009-1010.

17. White, A., P. Handler, and E. L. Smith. 1964. Principles of Biochemistry, McGraw-Hill Book Co., New York. Third ed. 387-392.

18. Rall, T. W., and A. L. Lehninger. Glutathione reductase of animal tissues. J. Biol. Chem. 194:119-130.

19. Dreyfus, P. M. 1961. The quantitative histochemical distribution of thiamine in deficient rat brain. J. Neurochem. 8:139-145.

20. McCandless, D. W., and S. Schenker. 1968. Encephalopathy of thiamine deficiency: studies of intracerebral mechanisms. J. Clin. Invest. 47:2268-2280.

21. Hsu, G. M., and B. F. Chow. 1960. Effect of thiamine deficiency on glutathione contents of erythrocytes and tissues in the rat. Proc. Soc. Exp. Biol. Med. 104:178-180.

22. McKusick, V. A. 1979. Mendelian Inheritance in Man. Johns Hopkins University Press, Baltimore. Fifth ed. 698.

23. Nadi, N. S., J. I. Nurnberger, and E. S. Gershon. 1984. Muscarinic cholinergic receptors on skin fibroblasts in familial affective disorder. $N$. Engl. J. Med. 311:225-230.

24. Childs, B. 1970. Sir Archibald Garrod's conception of chemical individuality: a modern appreciation. N. Engl. J. Med. 282:71-77.

25. Blass, J. B., and G. E. Gibson. 1979. Genetic factors in WernickeKorsakoff syndrome. Alcohol. Clin. Exp. Res. 3:126-134.

26. Mukherjee, A. B., F. Ghazanfari, S. Svoronos, R. C. Staton, T. Nakada, and I. L. Kwee. 1986. Transketolase abnormality in tolazamideinduced Wernicke's encephalopathy. Neurology. 36:1508-1510. 